\title{
BMJ Open Trends in HIV testing in the UK primary care setting: a 15-year retrospective cohort study from 2000 to 2015
}

\author{
Mark Gompels, ${ }^{1}$ Skevi Michael, ${ }^{2}$ Charlotte Davies, ${ }^{3}$ Tim Jones (D) ,, ${ }^{3,4}$ \\ John Macleod, ${ }^{3,5}$ Margaret May (i) ${ }^{3,5}$
}

To cite: Gompels M, Michael S, Davies C, et al. Trends in HIV testing in the UK primary care setting: a 15 -year retrospective cohort study from 2000 to 2015. BMJ Open 2019;9:e027744. doi:10.1136/ bmjopen-2018-027744

- Prepublication history and additional material for this paper are available online. To view these files, please visit the journal online (http://dx.doi. org/10.1136/bmjopen-2018027744).

Received 08 November 2018 Revised 28 August 2019 Accepted 30 September 2019

Check for updates

(C) Author(s) (or their employer(s)) 2019. Re-use permitted under CC BY-NC. No commercial re-use. See rights and permissions. Published by BMJ.

For numbered affiliations see end of article.

Correspondence to Dr Charlotte Davies; Charlotte.Davies@bristol.ac.uk

\section{ABSTRACT}

Objectives To estimate trends in HIV testing, positivity and prevalence in UK primary care for 2000-2015 as part of a wider investigation into reasons for late diagnosis of HIV. Design Retrospective cohort study using the Clinical Practice Research Datalink (CPRD) which is derived from computerised clinical records produced during consultations in primary care.

Setting 404 general practices in England.

Participants 5979598 adults aged $\geq 16$ years registered between 2000 and 2015 with 45093761 person years of observation.

Outcomes Annual HIV testing rates, proportion of positive tests and prevalence of HIV-infected people recorded in primary care 2000-2015.

Results HIV testing in primary care increased from 2000 to 2010, but then declined. Testing was higher in females than in males and in those aged 16-44 years compared with older adults. Rates per 100000 in women aged 16-44 years were 177 (95\% Cl 167 to 188); 1309 (95\% Cl 1282 to 1336); 1789 (95\% Cl 1757 to 1821) and 839 (95\% Cl 817 to 862$)$ in 2000, 2005, 2010 and 2015, respectively, and for non-pregnant women: 22.5 (95\% Cl 19 to 26); 134 (95\% Cl 125 to 143); 262 (95\% Cl 250 to 275); 190 (95\% Cl 179 to 201). For men aged 16-44 years rates were: 26 (95\% $\mathrm{Cl} 22$ to 29$) ; 107$ (95\% Cl 100 to 115); 196 (95\% Cl 185 to 206); 137 (95\% Cl 127 to 146). Over the study period, there were approximately two positive results per 1000 HIV tests. Men were eightfold more likely to test positive than women. The percentage of HIV diagnoses among adults recorded in CPRD may be as low as 55\% in London and $67 \%$ in the rest of the UK. Conclusions HIV testing rates in primary care peaked in 2010 and subsequently declined. Access to testing was higher for women despite the prevalence of HIV being higher in men.

Implications and further research needed Opportunities remain in primary care for increasing HIV testing to prevent costly late diagnoses and decrease HIV transmission. Interventions to improve targeting of tests and increase adherence to HIV testing guidelines are needed in primary care.

\section{INTRODUCTION}

HIV testing in primary care is an important component of the strategy to diagnose HIV
Strengths and limitations of this study

- We investigated trends in HIV testing in primary care using high quality data from the Clinical Practice Research Datalink (CPRD) which is derived from computerised clinical records produced during consultations in primary care in England.

- CPRD provided anonymised primary care records on patients registered between 2000 and 2015 in 404 primary care practices in England which is likely to be representative of the general patient population.

- A limitation of the study is that not all general practices contribute data to CPRD and therefore we cannot know whether the sample was representative.

- A major strength of the study was the large number of patients, nearly 6 million, which allowed us to contrast trends in HIV testing rates in primary care by sex, age, deprivation, rural/urban location and whether in London or not.

- Data were available for 15 years of follow-up allowing us to show that HIV testing in primary care in England increased between 2000 and 2010, but then declined up to 2015

earlier and reduce transmission of HIV. In 2015 there were an estimated $89800(95 \%$ credible interval (CrI) 87100 to 94800 ) people living with HIV in England of whom approximately $15 \%$ (CrI 12\%-19\%) were unaware of their infection. ${ }^{1}$ Of those individuals newly diagnosed with HIV in 2015, $39 \%$ were diagnosed late, defined as having a CD 4 count below 350 cells $/ \mathrm{mL}$ within 3 months of diagnosis. ${ }^{2}$ An estimated 1 in 4 of newly diagnosed individuals experienced a missed opportunity for an earlier diagnosis within the healthcare system in the preceding year. ${ }^{3}$ Late diagnosis of HIV is associated with increased hospitalisations, decreased life expectancy ${ }^{4-7}$ and higher treatment and care costs to the National Health Service (NHS) ${ }^{8}$ Importantly, individuals with undiagnosed HIV are likely to 
be responsible for the majority of transmissions because successfully treated individuals are unlikely to infect others. $^{9}$

Enhanced HIV testing is considered to be cost-effective in areas with a local diagnosed HIV prevalence that exceeds 2 per 1000 in adults aged $15-59$ years. ${ }^{210}$ In these high HIV prevalence areas recommendations are an HIV test should be routinely offered to all new general practitioner (GP) registrations, those undergoing tests for other sexually transmitted infections or having blood tests for any reason, and all new hospital medical admissions. ${ }^{211}$ However, the majority of people with HIV seek medical care for a related condition several times prior to their HIV diagnosis. ${ }^{1213}$ This may be presenting to general practice or hospital care. But without a high degree of clinical suspicion, the diagnosis is often missed. ${ }^{14}$ The British HIV Association(BHIVA) has published a list of indicator diseases that are more commonly found in those who are HIV positive than negative. ${ }^{15}$ HIV testing is recommended in these cases, but recent surveys suggest poor adherence to guidelines. ${ }^{16}{ }^{17}$ Given the increase in HIV prevalence over time we would expect that there would be an increase in GP testing for HIV.

Evidence from systematic reviews shows that there are often many barriers to testing experienced by patients and equally by healthcare professionals (HCP).$^{18-20}$ Patients presenting with clinical indicator conditions to their GP provide a valuable opportunity to diagnose HIV and avoid hospitalisations due to late diagnosis. ${ }^{21}$ Research has shown that the majority of patients (up to $75 \%$ ) newly diagnosed with HIV had been seen in the healthcare system within the 12 months prior to their diagnosis resulting in a missed opportunity to test. ${ }^{12} 1422{ }^{23} \mathrm{Opt}$ out HIV testing has been shown to be feasible, acceptable and cost effective in eight pilot studies conducted in community, primary and secondary care settings in high prevalence areas across England. ${ }^{24}$ However, no recent evidence is available to know if HIV testing in primary care has been increasing and guidelines have been implemented over the country and not just in high risk areas. ${ }^{16} 17$

HIV testing in primary care has been reported only for the years 1995-2005 using data from the UK General Practice Research Database (GPRD).$^{25}$ This study showed that testing in primary care remained low, but increased steadily. Our main objective was to analyse data from the same source collected between the years 2000 and 2015 to study if HIV testing trends continued to increase in primary care over this extended time period. In addition we investigated differences in HIV testing rates and HIV diagnosis by demographic characteristics and estimated the prevalence of HIV recorded in primary care and compared it with estimates from national surveillance.

\section{METHODS}

\section{Population and data}

We used data from the Clinical Practice Research Datalink (CPRD), previously known as the GPRD, which is derived from computerised clinical records produced during consultations in primary care. The CPRD database contains information from GP practices in the UK using the Vision software system (roughly 9\% of UK practices) who consent to data collection; the sample is broadly representative of the adult UK population. ${ }^{26}$ Only GP practices in England are eligible for linkage to other data sets such as hospital admissions and practices can opt out of linkage. CPRD provided anonymised primary care records and linked secondary care and mortality records on patients registered between 2000 and 2015 in 404 primary care practices in England. Data were available on nearly 6 million people aged over 16 years old. GPs enter data on tests, diagnoses and symptoms using Read codes that are a hierarchical alphanumeric system similar to, but more extensive than International Classification of Disease (ICD) codes. The list of Read codes used to identify (1) HIV tests ${ }^{25}$ (2) HIV diagnoses ${ }^{25}$ (3) pregnancy/delivery/abortion ${ }^{27}$ and (4) additional CPRD browser pregnancy medcodes is listed as appendices 1 to 4 , respectively, in the online supplementary file. We used individual level quintiles of the Index of Multiple Deprivation (IMD), 2015. ${ }^{28}$ Practices were classified as rural, urban conurbation or city/town at lower super output level (a small area geographic boundary of around 1500 people) in England based on Office for National Statistics classifications, 2011, ${ }^{29}$ and as within or outside London. Ethnicity was grouped as Asian, Black African, Black Caribbean, Other, White and unknown based on linked Hospital Episode Statistics data.

We used national surveillance data from Public Health England (PHE) on testing in primary care derived from general practices that submit HIV tests to laboratories participating in the Sentinel Surveillance of Blood Borne Virus Testing (SSBBV). These practices cover 35\% of England's primary care population. HIV testing data are captured from $66 \%$ of the primary care population in extremely high prevalence areas $(>5 / 1000), 37 \%$ within high prevalence areas $(>2 / 1000)$ and $29 \%$ within low prevalence areas. These data exclude any point of care tests carried out by GPs, and tests carried out as part of antenatal screening. The latest data available on testing rates and positivity were for $2015 .^{30}$ Data on HIV prevalence were derived from the HIV and AIDS Reporting System (HARS) and for earlier years the Survey of Prevalent HIV Infections Diagnosed (SOPHID) available from PHE. ${ }^{2}$ These data were available up to 2015.

\section{Patient and public involvement}

Public and patients were not involved in the design of this study. Patient data from general practices were contributed via CPRD and PHE surveillance as stated earlier.

\section{Statistical methods}

HIV testing rate, positivity and prevalence of HIV recorded in primary care

Using data from CPRD we estimated the HIV testing rates for each year between 2000 and 2015, overall and by patient demographics. Testing rates were estimated 
for males and females, for all ages and grouped by age (16-44, $\geq 45$ years, chosen to match the study by Evans et $\left.a l^{25}\right)$. We also estimated rates separately according to whether the practice was in London or not, and by type of location. For each calendar year, the denominator used to calculate the HIV testing rate was the number of patients who were in the CPRD cohort in that year satisfying the following inclusion criteria:

1. They were registered before 30 June of that year.

2. They did not transfer to another practice or die before 30 June of that year.

3. They were in the same practice for at least 6 months.

4. They had not previously tested positive for HIV.

The numerator was the number of HIV tests carried out within the relevant year. For each patient in the denominator, the number of tests was calculated, disregarding repeat tests that were within a 3-month period. Any test done or registered more than 90 days after the first recorded positive test was ignored.

As the majority of HIV tests in women are carried out as part of antenatal screening, analyses for females were repeated excluding these tests. We identified women who were pregnant using either delivery dates or Read codes as follows:

1. Delivery (birth) dates associated with the females in our data: An HIV test was considered antenatal if it occurred between 3 and 9 months before the recorded delivery date.

2. Read codes indicating any sign of pregnancy (antenatal): In this case an HIV test was considered antenatal if it occurred within 6 months from the day the Read code was recorded.

3. Read codes associated with the postpartum period: In this case the HIV test was considered antenatal if it occurred within 3-10 months before the corresponding record.

4. Read codes indicating any sign of miscarriage or abortion: An HIV test was recorded as antenatal if it occurred between 3 months prior to 3 months after the corresponding record.

The Read codes associated with pregnancy are listed in the online supplementary material. The antenatal HIV tests were excluded from the numerator and the corresponding patients were removed from the denominator for the related period as well.

We plotted the trends in HIV testing rates per 100 000 person years for 2000-2015 separately for men and women (including and excluding antenatal HIV tests) for all adults and restricted to those aged 16-44 years old. In addition, we calculated the annual proportion of HIV tests that were positive for each year to investigate whether testing improved in terms of targeting higher risk individuals during the later years.

For the years 2005, 2010 and 2015, we estimated and tabulated HIV testing rates and incidence rate ratios (IRRs) with 95\% CI from Poisson models for males and females separately according to whether practice was in London or not, by age, ethnicity, IMD and by type of
Table 1 Patient and practice demographics

\begin{tabular}{|c|c|c|c|}
\hline $\begin{array}{l}\text { Demographic } \\
\text { variable }\end{array}$ & Group & Frequency & Percentage (\%) \\
\hline \multirow[t]{3}{*}{ Gender } & Males & 2871884 & 48.03 \\
\hline & Females & 3107562 & 51.97 \\
\hline & Other/unknown & 152 & 0.00 \\
\hline \multirow[t]{2}{*}{ Age (in 2015) } & $16-44$ & 2684443 & 44.89 \\
\hline & $>44$ & 3295155 & 55.11 \\
\hline \multirow[t]{6}{*}{ Ethnicity } & Asian & 147295 & 2.46 \\
\hline & Black African & 45632 & 0.76 \\
\hline & $\begin{array}{l}\text { Black } \\
\text { Caribbean }\end{array}$ & 28558 & 0.48 \\
\hline & Other & 118934 & 1.99 \\
\hline & White & 3328189 & 55.66 \\
\hline & Unknown & 2310990 & 38.65 \\
\hline \multirow[t]{3}{*}{ Region } & Outside London & 4693116 & 78.49 \\
\hline & London & 1129924 & 18.90 \\
\hline & Unknown & 156558 & 2.62 \\
\hline \multirow[t]{4}{*}{ Urban/rural } & $\begin{array}{l}\text { Urban } \\
\text { (conurbation) }\end{array}$ & 2134497 & 35.70 \\
\hline & $\begin{array}{l}\text { Urban (city/ } \\
\text { town) }\end{array}$ & 2991079 & 50.02 \\
\hline & Rural & 697452 & 11.66 \\
\hline & Unknown & 156558 & 2.62 \\
\hline \multirow{4}{*}{$\begin{array}{l}\text { Patient IMD } \\
\text { (2015) } 1=\text { least } \\
\text { deprived, ..., } \\
5=\text { most deprived }\end{array}$} & Quintile 1 & 1285213 & 21.49 \\
\hline & Quintiles 2,3,4 & 3564936 & 59.62 \\
\hline & Quintile 5 & 964853 & 16.14 \\
\hline & Unknown & 164596 & 2.75 \\
\hline \multirow{4}{*}{$\begin{array}{l}\text { Practice IMD } \\
\text { (2015) } 1=\text { least } \\
\text { deprived, ..., } \\
5=\text { most deprived }\end{array}$} & Quintile 1 & 1249293 & 20.89 \\
\hline & Quintiles 2,3,4 & 3702313 & 61.92 \\
\hline & Quintile 5 & 871434 & 14.57 \\
\hline & Unknown & 156558 & 2.62 \\
\hline
\end{tabular}

IMD, Index of Multiple Deprivation.

location. To validate our estimates of HIV testing rates recorded in CPRD, we compared them with those from national surveillance data collected by PHE for $2015 .^{30}$ Finally, we estimated the prevalence of diagnosed HIV recorded in CPRD and compared this with estimated prevalence from national surveillance data collected by PHE using SOPHID and HARS to determine the proportion of all HIV diagnoses that were recorded in CPRD . Data analysis was performed using STATA V.14.

\section{RESULTS}

Data were available on 5979598 distinct patients with 45 093761 (males 22,155,768; females 22,937,630) person years of observation. The demographic characteristics of included individuals are shown in table 1 . There were less males $(48 \%)$ than females $(52 \%)$. Practices $(15 \%)$ and individuals $(16 \%)$ in the most deprived quintile of IMD were under-represented in CPRD. The total number of 


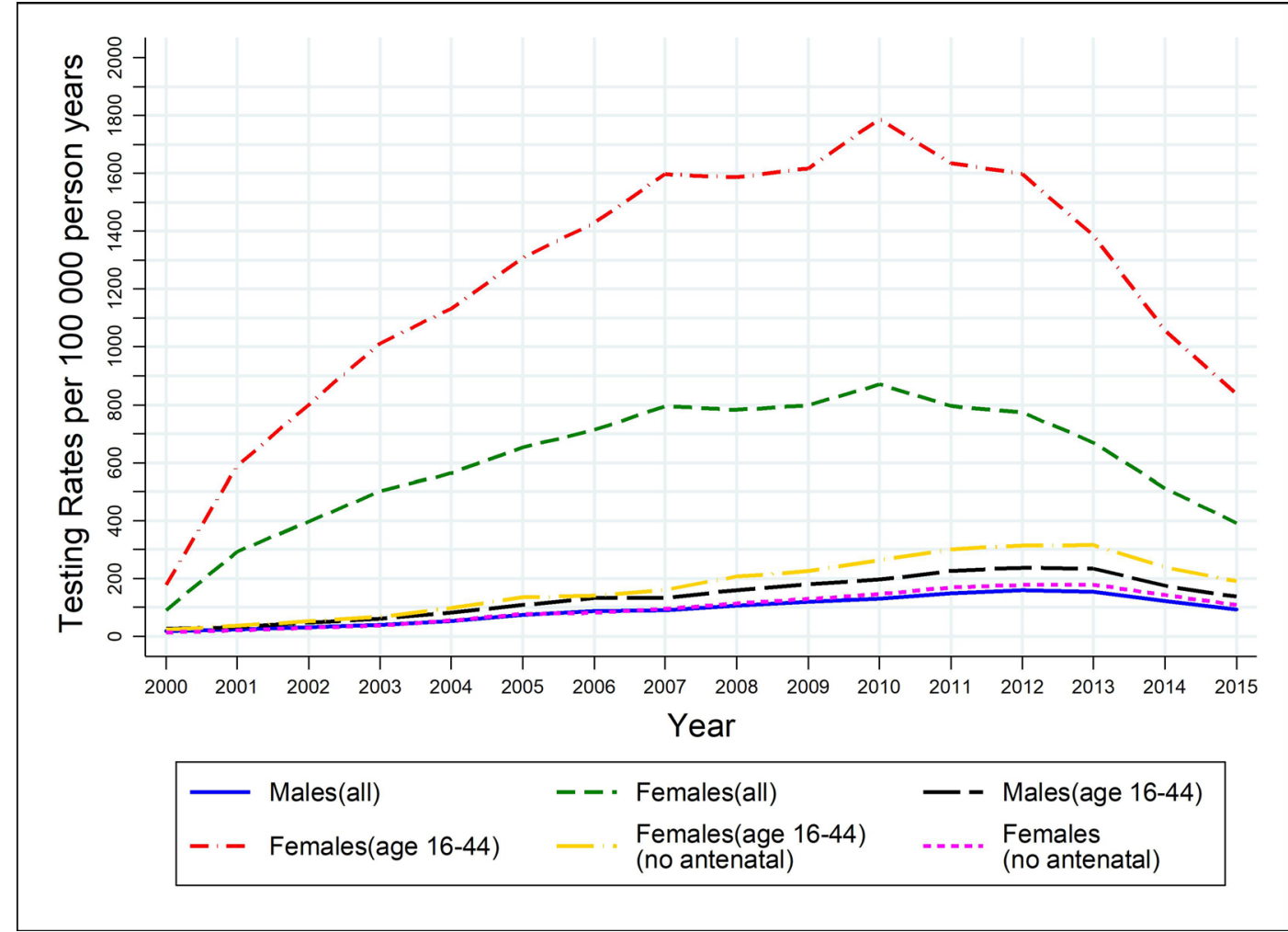

Figure 1 Trend in HIV testing rates per 100000 person years for the period 2000-2015 by gender and age group, with and without inclusion of antenatal testing.

HIV tests recorded in CPRD between 2000 and 2015 was 159115 of which $357(0.2 \%)$ were positive.

\section{Trends in HIV testing rates 2000-2015 in primary care}

Figure 1 shows the trend in HIV testing rates per 100000 person years for the period 2000-2015 by gender and age group, with and without inclusion of antenatal testing. The main reason for HIV testing among women of childbearing age was antenatal screening: the testing rates (per 100000 person-years) in all women aged 16-44 increased from 177 (95\% CI 167 to 188 ) in 2000 to 1789 (95\% CI

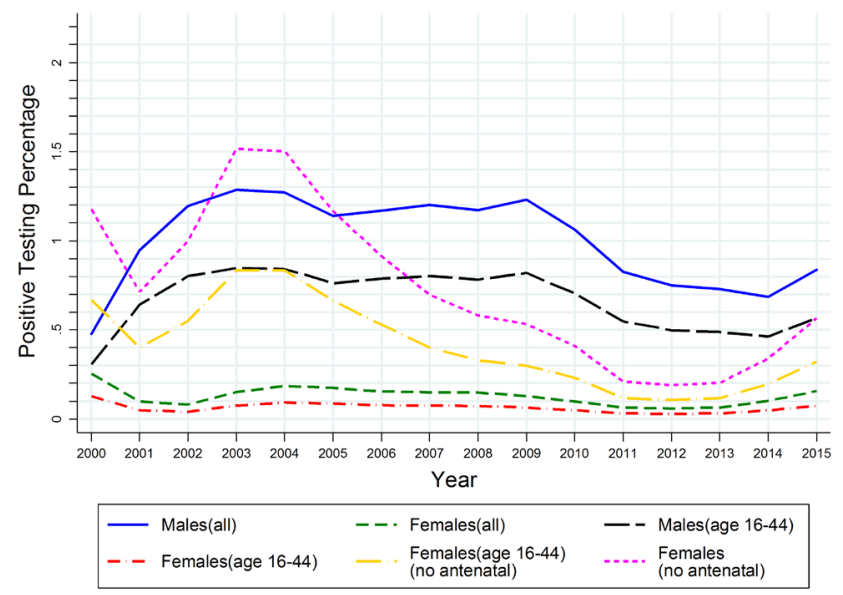

Figure 2 Trend in the percentage of HIV tests that were positive for the period $2000-2015$ by gender and age group, with and without inclusion of antenatal testing.
1757 to 1821 ) in 2010 and then decreased to 839 (95\% CI 817 to 862 ) in 2015, with the corresponding figures being 23 (95\% CI 19 to 26), 262 (95\% CI 250 to 275) and 190 (95\% CI 179 to 201) when antenatal testing was excluded. For males the corresponding rates were 26 (95\% CI 22 to 29), 196 (95\% CI 185 to 206) and 137 (95\% CI 127 to 146), which are lower than rates for females even when antenatal tests are excluded. HIV testing rates in primary care peaked in females in 2010 (figure 1) and have declined markedly since then. In men and women not tested antenatally, HIV testing rates increased until 2012-2013, but have declined since. Similar patterns were seen when data were restricted to those aged 16-44 years only, except that rates were much higher in younger adults compared with those aged 45 years and over (online supplementary table 1 all adults, online supplementary table 2 for those aged 16-44 years).

\section{Trends in positive HIV diagnosis in primary care}

Although the number of HIV tests was much higher in women, more men tested positive: 196/20,328 (0.96\%) men compared with $161 / 138,787(0.12 \%)$ women. This was skewed by a very low rate of positive diagnoses in younger females who were screened antenatally. The smoothed trend in the percentage of tests that were positive for men and women of different ages is shown in figure 2 (plot of raw data is shown in online supplementary figure). Percentage positive (excluding antenatal tests) was similar in men and women before 2005, but declined more sharply in women thereafter. The 
percentage of tests that were positive peaked around 2003 and has fallen sharply since 2010, indicating that there is no evidence of better targeting of testing to individuals in later years.

\section{HIV testing rates in practices within and outside London, by age and deprivation index}

HIV testing rates were twofold higher in London compared with outside London for both men and women in 2005 and this differential increased in 2010 and 2015. Tables 2 and 3 give the testing rates for years 2005, 2010 and 2015 for males and females (excluding antenatal tests), respectively, stratified by whether the practices were in London or outside London. Data for all years between 2000 and 2015 are given for all adults (online supplementary table 1 ) and for adults aged 16-44 years (online supplementary table 2). In more recent years practices outside London but in conurbations had higher rates than those in cities or towns, which, in turn, had higher rates than rural practices. Although testing rates in men in London practices decreased between 2010 and 2015 overall from 273 (95\% CI 251 to 295) to 246 (95\% CI 225 to 266) per 100000 person-years, there was evidence of a shift in targeting of testing since rates increased in older men from 151 (95\% CI 127 to 176 ) to 180 (95\% CI 154 to 206) per 100000 person years and in the most deprived quintile from 415 (95\% CI 351 to 480 ) to 565 (95\% CI 487 to 643) per 100000 person years. This targeting effect was also seen among women in London practices, but not in practices outside London. However, in 2015 in London it remained the case that older people were less likely to be tested: IRR for age $\geq 45$ compared with 16-44 years was 0.59 (95\% CI 0.50 to 0.71 ) for men and 0.46 (95\% CI 0.38 to 0.55$)$ in women. The corresponding IRRs for outside London were much lower: IRR for age $\geq 45$ compared with 16-44 years was 0.37 (95\% CI 0.32 to 0.43 ) in men and 0.18 (95\% CI 0.16 to 0.21$)$ in women. In contrast, by 2015 the most deprived group were two/threefold more likely to be tested than the least deprived, depending on gender and locality, with IRR for IMD quintile 5 versus 1 increasing markedly from 2005 to 2015 (table 2 (males) and table 3 (females)).

\section{HIV testing rates and positivity according to national surveillance data}

For comparison, national surveillance data for 2015 estimated that general practices in extremely high prevalence areas (defined as greater than $5 / 1000$ population, comparable with 'London' in our CPRD study) carried out the highest number of tests per practice population 860 per 100000 person years. This was nearly double the coverage rate of general practices in high diagnosed prevalence areas (defined as greater than 2/1000 population), which was estimated at 440 per 100000 person years, and ten times the coverage rate among general practices in low diagnosed prevalence areas, which was estimated at 90 per 100000 person years. The estimates of HIV testing rates from surveillance were higher than our estimates from CPRD (tables 2 and 3). The proportion of positive tests among those tested in primary care estimated from SSBBV surveillance data was $0.4 \%$ in $2015 .{ }^{30}$ This varied from $0.5 \%$ in very high prevalence areas to $0.2 \%$ in low prevalence areas and was consistent with our estimated positivity (figure 2 ).

\section{Prevalence of recorded HIV in CPRD and comparison with national surveillance estimates}

In 2015 the prevalence of diagnosed HIV recorded in CPRD was 2.8 per 1000 adult patients in London practices and 0.8 per 1000 in the rest of the UK (table 4). According to PHE surveillance, in 2015 HIV prevalence in UK was estimated to be 1.6 per 1000 , and excluding undiagnosed HIV was 1.3 per 1000 population. ${ }^{2}$ The HIV prevalence in London was estimated to be 4.7 per 1000 , substantially higher than the rest of the UK at 1.1 per 1000. The corresponding observed prevalence, that is, excluding undiagnosed cases of HIV, was 4.2 and 0.9 per 1000 population in London and the rest of the UK, respectively. ${ }^{2}$ However, these percentages are likely to be overestimated as children aged $<16$ years were not included in the CPRD calculations of prevalence but were included in PHE data. In general practices in London, prevalence of HIV recorded in CPRD was higher for males, older individuals, Black African ethnicity and most deprived quintile (table 4) with a similar pattern in practices outside London except that prevalence did not vary by age.

\section{DISCUSSION}

\section{Statement of principal findings}

Our analysis of CPRD data on GP consultations recorded on approximately 6 million people living in the UK over a 15-year period shows that the initial rise in HIV testing seen in primary care between 2000 and 2010 reversed with a significant drop in the testing rates for HIV in primary care from 2010. This is an unexpected finding as throughout this period prevalence of HIV has been increasing which should have engendered higher rates of testing in primary care, given the NICE recommendations on testing, which would increase with increased prevalence. ${ }^{31}{ }^{32}$ HIV testing rates in primary care were higher in women than men throughout the study period, even when tests for antenatal screening were excluded, despite HIV prevalence being higher in men. This resulted in men being eightfold more likely to test positive than women in this setting. Over the 15 -year period of the study, there were approximately two positive results per 1000 HIV tests. We did not find evidence of better targeting of HIV testing to individuals in more recent years as the percentage of tests that were positive peaked around 2003. Many individuals at high risk of HIV infection may choose to test in settings other than general practice, such as sexual health clinics, which might make it harder to target HIV testing among the population attending primary care. 


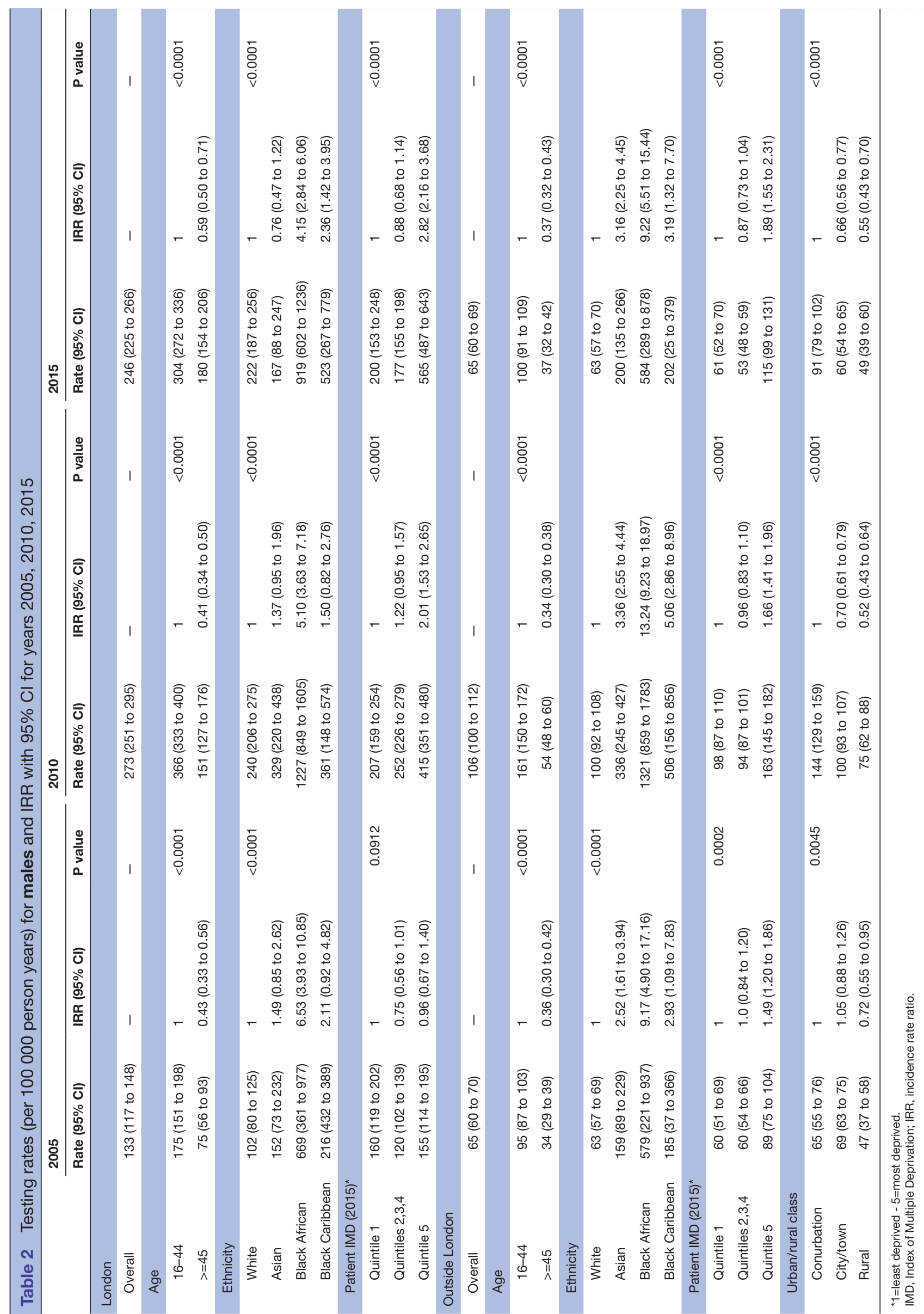




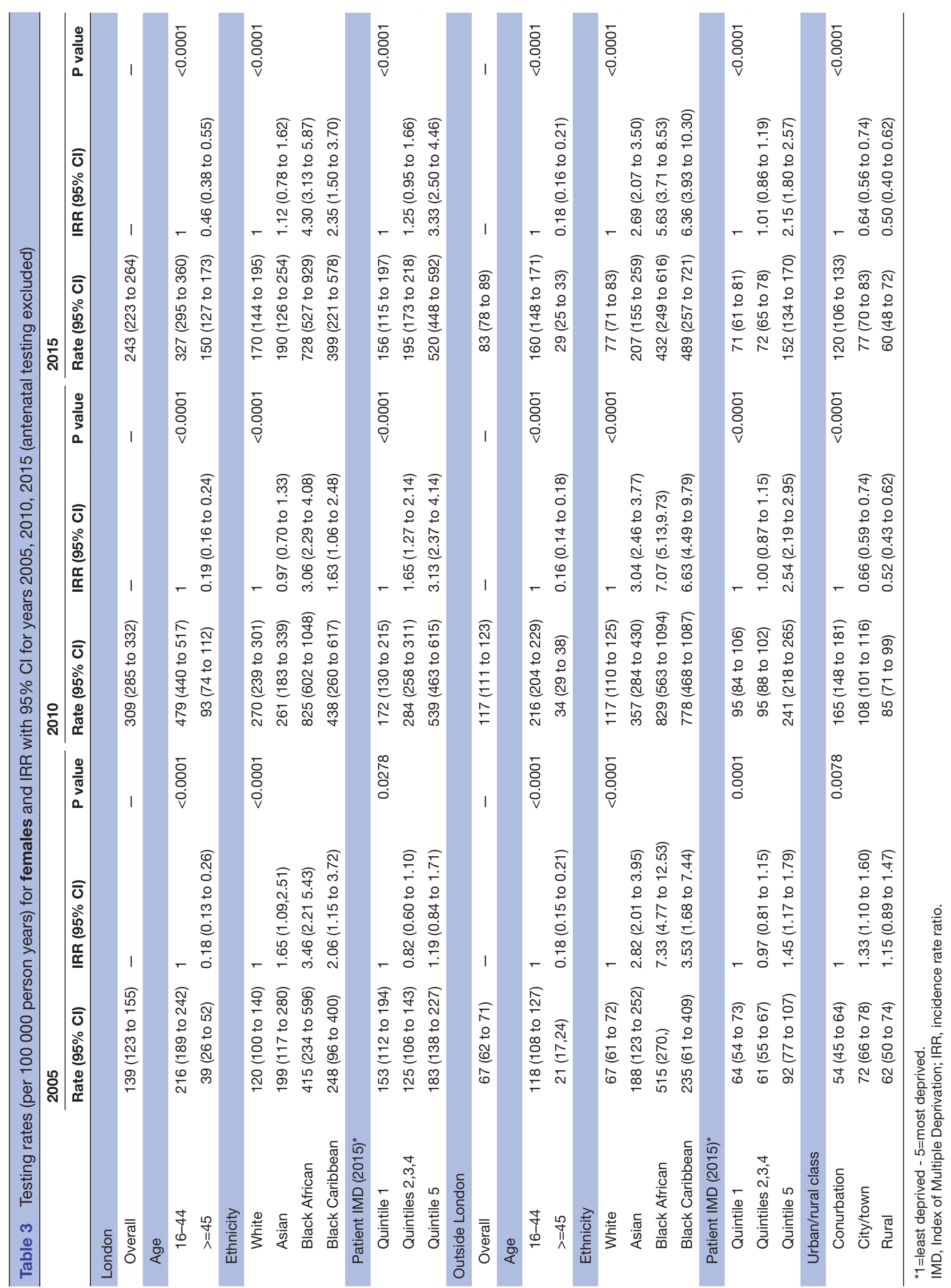


Table 4 Prevalence (with 95\% Cl) of diagnosed HIV recorded in CPRD (per 100000 persons) by gender, age, ethnicity and patient IMD, for London and outside London

\section{Prevalence (95\% Cl)}

$20052010 \quad 2015$

\begin{tabular}{|c|c|c|c|}
\hline \multicolumn{4}{|l|}{ London } \\
\hline All & 140 (129 to 151$)$ & 230 (216 to 244$)$ & 282 (267 to 297 ) \\
\hline \multicolumn{4}{|l|}{ Gender } \\
\hline Males & 191 (172 to 209) & 294 (271 to 317 ) & 369 (344 to 395) \\
\hline Females & 91 (78 to 103) & 170 (153 to 187$)$ & 199 (181 to 217 \\
\hline \multicolumn{4}{|l|}{ Age } \\
\hline $16-44$ & 168 (152 to 184$)$ & 234 (215 to 253) & 229 (210 to 249) \\
\hline$>44$ & 103 (88 to 117$)$ & 226 (205 to 247 ) & 341 (316 to 365$)$ \\
\hline \multicolumn{4}{|l|}{ Ethnicity } \\
\hline White & 127 (112 to 143$)$ & 183 (164 to 202$)$ & 224 (202 to 246$)$ \\
\hline Asian & 45 (17 to 72$)$ & 84 (50 to 119$)$ & 96 (60 to 131$)$ \\
\hline Black African & 1465 (1205 to 1726$)$ & 2350 (2055 to 2646 ) & 2597 (2294 to 2899) \\
\hline Black Caribbean & 195 (97 to 294) & 431 (291 to 572 ) & 538 (381 to 695 ) \\
\hline \multicolumn{4}{|l|}{ Patient IMD (2015) } \\
\hline Quantile 1 & 32 (19 to 45$)$ & 86 (65 to 107$)$ & 121 (96 to 146$)$ \\
\hline Quantiles 2,3,4 & 136 (122 to 149$)$ & 212 (195 to 228 ) & 256 (238 to 274$)$ \\
\hline Quantile 5 & 268 (230 to 306 ) & 444 (397 to 491 ) & 544 (492 to 596) \\
\hline \multicolumn{4}{|l|}{ Outside London } \\
\hline All & 38 (36 to 41 ) & 64 (61 to 67$)$ & 81 (77 to 85$)$ \\
\hline \multicolumn{4}{|l|}{ Gender } \\
\hline Males & 50 (46 to 54 ) & 81 (76 to 86 ) & 105 (99 to 110 ) \\
\hline Females & 26 (23 to 29$)$ & 48 (44 to 52 ) & 58 (54 to 62) \\
\hline \multicolumn{4}{|l|}{ Age } \\
\hline $16-44$ & 55 (51 to 59$)$ & 78 (72 to 83 ) & 82 (76 to 87 ) \\
\hline$>44$ & 22 (19 to 25$)$ & 52 (48 to 56 ) & 80 (76 to 85$)$ \\
\hline \multicolumn{4}{|l|}{ Ethnicity } \\
\hline White & 29 (26 to 32$)$ & 46 (43 to 50 ) & 60 (56 to 64$)$ \\
\hline Asian & 37 (16 to 59$)$ & 40 (21 to 59$)$ & 55 (34 to 76$)$ \\
\hline Black African & 2537 (2110 to 2964) & 3663 (3236 to 4091 ) & 3933 (3514 to 4353 ) \\
\hline Black Caribbean & 135 (35 to 236$)$ & 347 (195 to 499) & 484 (308 to 660) \\
\hline \multicolumn{4}{|l|}{ Patient IMD (2015) } \\
\hline Quantile 1 & 19 (16 to 23$)$ & 31 (26 to 35 ) & 42.58 (37 to 48 ) \\
\hline Quantiles 2,3,4 & 35 (32 to 38 ) & 60 (56 to 65$)$ & 77 (72 to 81) \\
\hline Quantile 5 & 82 (72 to 91$)$ & 132 (121 to 144$)$ & 159 (146 to 172$)$ \\
\hline
\end{tabular}

IMD, Index of Multiple Deprivation.

The pattern of HIV testing has also changed over time. Testing was twofold higher in London than elsewhere and has increased in the groups and areas of high deprivation within London. This is reassuring as it also reflects the higher prevalence of HIV in these areas and indicates that HIV testing has become more geographically targeted. Overall, testing rates were higher in urban conurbations and cities than in rural areas reflecting the national prevalence figures. ${ }^{2}$ Younger people were more likely to be tested than those aged 45 years and over, which reflects the incidence pattern for HIV. However, our data show an increasing trend in the rate of testing among the older age group in London, but not elsewhere, which may have been driven by the recognition that among those with HIV infection the proportion diagnosed late is higher in older age groups. ${ }^{33}$

In 2015, the prevalence of HIV recorded in CPRD was over threefold higher in London than elsewhere, but 
overall was substantially lower than the prevalence of diagnosed HIV estimated from PHE surveillance. ${ }^{2}$ This may be due to HIV-positive individuals not using primary care or to non-disclosure of their HIV status to their GP, not recording of the diagnosis on GP systems, or to CPRD not including sufficient practices with high HIV prevalence. CPRD is broadly representative of primary care in the UK, but the UK HIV epidemic is concentrated in cities with approximately half of HIV-positive individuals living in London. ${ }^{2}$ The estimated percentage of HIV diagnoses among adults that were recorded in CPRD increased between 2005 and 2015 but was still substantially lower in London than elsewhere. This trend may reflect the ageing HIV population's greater requirement of primary care services, decrease in stigma of disclosure, or better transfer and recording in primary care of positive results of HIV tests carried out in other settings in later years.

\section{Strengths and weaknesses of the study}

This study is very large with data from nearly six million patients followed over 15 years with detailed primary care records. This detailed coverage enabled us to accurately measure HIV testing rates according to the important factors of deprivation, urbanisation, gender, ethnicity and age. Records were collected prospectively and electronically over a significant time period; therefore, we were able to show clearly the trends that have occurred. Our analysis and the data collection may be biased by several factors. The CPRD only includes a sample of general practices, but this is broadly representative of primary care in the UK, and, given the large numbers, this is a sufficient sample size for estimates of testing rates to be accurate. We have shown the CPRD slightly under-represents deprivation, in both individuals and GP practices. While this may be the case, given the very large sample size, we think that we can still draw valuable conclusions from this data. This study can only show the composite rates of testing in primary care. We were not able to categorise the different indications for an HIV test. What is clear, given the number of HIV positive patients, is that many patients will have been diagnosed in other healthcare settings, for example, PHE estimated that in England during $20165.9 \%$ and $7.3 \%$ of new diagnoses in men and women, respectively, were made in primary care. ${ }^{34}$ This implies that estimates of the prevalence of diagnosed HIV based on diagnoses recorded in CPRD will be underestimates for the UK which we have shown by comparing with surveillance data from PHE.

\section{Strengths and weaknesses in relation to other studies, discussing important differences in results}

HIV testing in primary care in the Netherlands also decreased between 2010 and 2015 despite similar guidelines encouraging more pro-active screening for HIV. ${ }^{35}$ Although HIV testing in primary care has declined, the rates of late diagnosis (CD4 count less than 350 cells $/ \mathrm{mL}$ ) have also declined from $50 \%$ in 2010 to $39 \%$ in $2015,{ }^{36}$ indicating a discordancy between the testing in primary care and diagnosis. This indicates that increased testing has likely occurred in other settings. Earlier diagnosis may be due to better detection in secondary care, either from screening or testing those with indicator conditions, or through other routes such as sexual health clinics, insurance requests or specialist testing services. Moreover, if testing has become better targeted in primary care and incidence in the consulting population is decreasing then even without an increase in testing, those who get tested may be tested earlier in the course of HIV infection leading to reduced rates of late diagnoses. However, we have shown a significant decline in HIV testing in primary care since the previous analysis by Evans et $a l^{25}$ on testing up to 2005 , and therefore we can look at increased testing in primary care as an option to improve early HIV detection rates.

Meaning of the study: possible explanations and implications for clinicians and policymakers

Since 2015, UK and international treatment guidelines ${ }^{37}$ for those diagnosed with HIV recommend immediate treatment with antiretroviral therapy due to findings from the START trial. ${ }^{38}$ This change, together with preexposure prophylaxis, has resulted in a decline in HIV infection rates for the last 2 years ${ }^{34}$. Nevertheless, there are still opportunities for diagnosing HIV earlier in primary care while testing rates remain very low. Current UK testing guidelines ${ }^{34}$ recommend people attending general practices in areas of high HIV prevalence should be offered an HIV test at registration or when having a blood test if they have not had an HIV test in the past 12 months. People newly diagnosed with an HIV indicator condition should also be offered an HIV test. The aim is to diagnose HIV earlier as late diagnosis of HIV is associated with increased morbidity and mortality. ${ }^{79} 40$ There are benefits for diagnosing HIV earlier both for the individual in terms of quality of life and life expectancy ${ }^{6}$ and a wider societal benefit of reduced transmission and lower NHS treatment costs.

\section{Unanswered questions and future research}

Although it is a public health imperative, and target, to increase HIV testing and diagnosis, it is unclear how this could be implemented in primary care. A literature review undertaken of public and HCP attitudes towards HIV testing in the UK showed that a proactive offer of an HIV test by the HCP was an important factor which could help increase testing rates. ${ }^{20}$ Reasons for low levels of HIV testing by the HCP include fear/concern of offending patients, inadequate knowledge/training on HIV, low awareness of current testing guidelines, underestimation of patient risk, insufficient time, competing priorities, perceived burdensome consent process and pre-test discussion. ${ }^{18-20} 41$ Studies indicate a need for education and training on HIV testing for HCP in primary care to overcome these barriers to testing. ${ }^{162}$ Adequate interventions are needed to address these barriers so individuals can receive a timely HIV test and with it the important 
treatment benefits and care if found to be HIV positive. Another literature review has provided evidence that HIV indicator conditions have the potential to be used more effectively as triggers for earlier HIV testing. ${ }^{43}$ Opt-out testing can facilitate increased HIV testing as has been evident from a trial in emergency care setting. ${ }^{44}$ When blood tests are carried out for any reason in primary care, there could also be an opt-out HIV test. Computer prompts based on risk algorithms are another strategy to support HIV testing ${ }^{45-49}$ which could be based on electronic health records such as those in CPRD.

Although the results shown here are for a UK-based population the methodology may be applicable to other healthcare systems. They provide accurate testing rates and detection rates in primary care which are measures of HIV testing that can be used for international comparisons. A key element for preventing transmission and late diagnosis of HIV is testing in primary care, based on a screening strategy or indicator conditions. ${ }^{50}$ These data inform us of the current situation on testing and will be useful in planning and evaluating interventions to improve this.

The data on the discrepancy between PHE and CPRD prevalence of HIV positive status being recorded are another finding of importance for planning. New testing strategies such as home test and rapid testing outside of standard healthcare settings may contribute to the decrease in testing in primary care. These need to have a strategy in their delivery to feed back to primary care to maximise the benefits to patients and their health networks.

\section{CONCLUSIONS}

HIV testing rates have declined in primary care in all age groups, although there has been a fall in late presentation. HIV testing rates are highest in London, and higher in urban areas than rural areas. Increased testing would likely increase the number of positive tests and help prevent late diagnosis. Further interventions to increase selectivity of testing (positive cases per test) may be required, either at the individual level using risk factors and HIV indicator conditions or at the practice level using knowledge of local HIV prevalence.

\section{Author affiliations}

${ }^{1}$ Department of Immunology, Southmead Hospital, North Bristol NHS Trust, Bristol, UK

${ }^{2}$ Institute of Statistical Science, School of Mathematics, University of Bristol, Bristol, UK

${ }^{3}$ Department of Population Health Sciences, Bristol Medical School, University of Bristol, Bristol, UK

${ }^{4}$ The National Institute for Health Research Applied Research Collaboration West (NIHR ARC West), University Hospitals Bristol NHS Foundation Trust, Bristol, UK ${ }^{5}$ The National Institute of Health Research Health Protection Research Unit (NIHR HPRU) in Evaluation of Interventions, University of Bristol, Bristol, UK

Acknowledgements We would like to thank the following authors; Joni Jackson, Natalia V. Lewis, Gene S Feder, Penny Whiting, Timothy Jones, John Macleod and
Maria Theresa Redaniel for sharing their medical codes to identify pregnancy, delivery and abortion used in our data analysis.

Contributors MG and MM planned the research study and were responsible for study design. JM and TJ advised on study design. CD applied for ethics approval and did the literature search. TJ and CD obtained data from the CPRD and helped with coding and extracting data. SM was responsible for statistical analyses, tables and graphs. MM, SM and MG wrote the first draft of the paper. All authors contributed to writing and revising the paper and agreed to submission. MM acts as guarantor for the conduct of the study, had full access to the data and made decision to publish.

Funding The study was supported by Research Capability Funding from North Bristol NHS Trust. This study is based in part on data from the Clinical Practice Research Datalink (CPRD) obtained under licence from the UK Medicines and Healthcare products Regulatory Agency. This report is independent research supported by the National Institute for Health Research (NIHR) Health Protection Research Unit in Evaluation of Interventions at University of Bristol in partnership with Public Health England. TJ's time is supported by the NIHR Collaboration for Leadership in Applied Health Research and Care West at University Hospitals Bristol NHS Foundation Trust. MM is also supported by the NIHR Biomedical Research Centre at University Hospitals Bristol NHS Foundation Trust and the University of Bristol. However, the interpretation and conclusions contained in this report are those of the authors and not necessarily those of the National Health Service, the $\mathrm{NIHR}$, the CPRD or the Department of Health.

Competing interests None declared.

Patient consent for publication Not required.

Ethics approval The protocol was submitted to and approved by the independent scientific advisory committee for the CPRD (protocol ISAC number 16_172A). The study was approved by the South West, Frenchay, Research Ethics Committee on 19 September 2016 (REC reference 16/SW/0286).

Provenance and peer review Not commissioned; externally peer reviewed.

Data availability statement All data relevant to the study are included in the article or uploaded as supplementary information.

Open access This is an open access article distributed in accordance with the Creative Commons Attribution Non Commercial (CC BY-NC 4.0) license, which permits others to distribute, remix, adapt, build upon this work non-commercially, and license their derivative works on different terms, provided the original work is properly cited, appropriate credit is given, any changes made indicated, and the use is non-commercial. See: http://creativecommons.org/licenses/by-nc/4.0/.

\section{ORCID iDs}

Tim Jones http://orcid.org/0000-0002-1199-8668

Margaret May http://orcid.org/0000-0002-9733-1003

\section{REFERENCES}

1 Brown AE, Kirwan PD, Chau C, et al. Towards elimination of HIV transmission, AIDS and HIV-related deaths in the UK - 2017 report. London: Public Health England, 2017.

2 Kirwan PC C, Brown AE, Delpech VC. HIV in the UK - 2016 report. London Public Health England; 2016.

3 Ellis S, Curtis H, Ong ELC, et al. HIV diagnoses and missed opportunities. Results of the British HIV association (BHIVA) national audit 2010. Clin Med 2012;12:430-4.

4 Chadborn TR, Delpech VC, Sabin CA, et al. The late diagnosis and consequent short-term mortality of HIV-infected heterosexuals (England and Wales, 2000-2004). AIDS 2006;20:2371-9.

5 Girardi E, Sabin CA, Monforte Antonella D'Arminio. Late diagnosis of HIV infection: epidemiological features, consequences and strategies to encourage earlier testing. J Acquir Immune Defic Syndr 2007;46 Suppl 1:S3-8.

6 May M, Gompels M, Delpech V, et al. Impact of late diagnosis and treatment on life expectancy in people with HIV-1: UK Collaborative HIV cohort (UK chiC) study. BMJ 2011;343:d6016.

7 Croxford S, Kitching A, Desai S, et al. Mortality and causes of death in people diagnosed with HIV in the era of highly active antiretroviral therapy compared with the general population: an analysis of a national observational cohort. Lancet Public Health 2017;2:e35-46.

8 Beck EJ, Mandalia S, Sangha R, et al. The cost-effectiveness of early access to HIV services and starting cART in the UK 1996-2008. PLoS One 2011;6:e27830. 
9 Rodger AJ, Cambiano V, Bruun T, et al. Sexual activity without condoms and risk of HIV transmission in Serodifferent couples when the HIV-positive partner is using suppressive antiretroviral therapy. JAMA 2016;316:171-81.

10 National Institute of Health and Care Excellence (NICE). HIV testing: increasing uptake among people who may have undiagnosed HIV. Economic assessment: resource impact of recommendations, 2016. Available: https://www.nice.org.uk/guidance/GID-PHG91/ documents/economic-report [Accessed Jul 2016].

11 National Institute of Health and Care Excellence (NICE). HIV testing: increasing uptake among people who may have undiagnosed HIV, 2016. Available: niceorguk/guidance/ng60 [Accessed Sep 2017].

12 Read P, Armstrong-James D, Tong CYW, et al. Missed opportunities for HIV testing-a costly oversight. QJM 2011;104:421-4.

13 Joore IK, Arts DL, Kruijer MJP, et al. Hiv indicator condition-guided testing to reduce the number of undiagnosed patients and prevent late presentation in a high-prevalence area: a case-control study in primary care. Sex Transm Infect 2015;91:467-72.

14 Burns FM, Johnson AM, Nazroo J, et al. Missed opportunities for earlier HIV diagnosis within primary and secondary healthcare settings in the UK. AIDS 2008;22:115-22.

15 British HIV Association. UK national guidelines for HIV testing 2008, 2008. Available: http://www.bhiva.org/HIVtesting2008.aspx [Accessed Apr 2016].

16 Elmahdi R, Gerver SM, Gomez Guillen G, et al. Low levels of HIV test coverage in clinical settings in the U.K.: a systematic review of adherence to 2008 guidelines. Sex Transm Infect 2014;90:119-24.

17 Hartney T, Kennedy I, Crook P, et al. Expanded HIV testing in highprevalence areas in England: results of a 2012 audit of sexual health commissioners. HIV Med 2014;15:251-4.

18 Deblonde J, De Koker P, Hamers FF, et al. Barriers to HIV testing in Europe: a systematic review. Eur J Public Health 2010;20:422-32.

19 Bolsewicz K, Vallely A, Debattista J, et al. Factors impacting HIV testing: a review - perspectives from Australia, Canada, and the UK. AIDS Care 2015;27:570-80.

20 Davies C, Gompels M, May M. Public and healthcare practitioner attitudes towards HIV testing: review of evidence from the United Kingdom (UK). Int STD Res Rev 2015;3:91-122.

21 Scognamiglio P, Chiaradia G, De Carli G, et al. The potential impact of routine testing of individuals with HIV indicator diseases in order to prevent late HIV diagnosis. BMC Infect Dis 2013;13:473.

22 Goodall L, Leen C. Late diagnosis of HIV: could this be avoided? Scott Med J 2011;56:84-6.

23 Joore IK, Reukers DFM, Donker GA, et al. Missed opportunities to offer HIV tests to high-risk groups during general practitioners' STI-related consultations: an observational study. BMJ Open 2016:6:e009194.

24 Health Protection Agency (HPA). Time to test for HIV: expanding HIV testing in healthcare and community services in England, 2011. Available: http://www.bhiva.org/documents/Publications/Time to test_final_report_Sept_2011.pdf [Accessed Sep 2017].

25 Evans HER, Mercer CH, Rait G, et al. Trends in HIV testing and recording of HIV status in the UK primary care setting: a retrospective cohort study 1995-2005. Sex Transm Infect 2009;85:520-6.

26 Herrett E, Gallagher AM, Bhaskaran K, et al. Data resource profile: clinical practice research Datalink (CPRD). Int J Epidemiol 2015;44:827-36.

27 Jackson J, Lewis NV, Feder GS, et al. Exposure to domestic violence and abuse and consultations for emergency contraception: nested case-control study in a UK primary care dataset. $\mathrm{Br} \mathrm{J}$ Gen Pract 2019;69:e199-207.

28 National Statistics. English indices of deprivation 2015. statistics on relative deprivation in small areas in England, 2015. Available: https:// www.gov.uk/government/statistics/english-indices-of-deprivation2015 [Accessed Apl 2016].

29 Rhodes SD, Vissman AT, Stowers J, et al. A CBPR partnership increases HIV testing among men who have sex with men (MSM): outcome findings from a pilot test of the CyBER/testing Internet intervention. Health Educ Behav 2011;38:311-20.

30 Public Health England (PHE). Health protection report. Annual report from the sentinel surveillance study of blood borne virus testing in England: data for January to December 2015, 2016. Available: https://assets.publishing.service.gov.uk/government/uploads/ system/uploads/attachment_data/file/540332/hpr2416_bbvs.pdf [Accessed Jul 2016].

31 National Institute for Health and Care Excellence (NICE). Increasing the uptake of HIV testing to reduce undiagnosed infection and prevent transmission among black African communities living in England. NICE Public Health guidance 33, 2011. Available: $\mathrm{http//:niceorguk} \mathrm{[Accessed} \mathrm{Oct} \mathrm{2014].}$

32 National Institute for Health and Care Excellence (NICE). Increasing the uptake of HIV testing among men who have sex with men. NICE Public Health Guidance 34, 2011. Available: http//:niceorguk [Accessed Sep 2014].

33 Tavoschi L, Gomes Dias J, Pharris A, et al. New HIV diagnoses among adults aged 50 years or older in 31 European countries, 200415: an analysis of surveillance data. Lancet HIV 2017;4:e514-21.

34 Nash SGF M, Gill ON, Connor N. HIV testing in England: 2017 report. London: Public Health England, 2017.

35 Joore IK, van Bergen JEAM, Ter Riet G, et al. Development and evaluation of a blended educational programme for general practitioners' trainers to stimulate proactive HIV testing. BMC Fam Pract 2018;19:36.

36 Public Health England (PHE). HIV: annual data tables. HIV surveillance data in the UK by demographic characteristics and geographical region, 2015. Available: https://www.gov.uk/ government/statistics/hiv-annual-data-tables [Accessed Jul 2016]

37 World Health Organisation (WHO). Guideline on when to start antiretroviral therapy and on pre-exposure prophylaxis for HIV. Geneva: World Health organization, 2015. Available: http://www.who. int/hiv/pub/guidelines/earlyrelease-arv/en [Accessed Jul 2017].

38 Lundgren JD, Babiker AG, Gordin F, et al. Initiation of antiretroviral therapy in early asymptomatic HIV infection. N Engl J Med 2015;373:795-807.

39 Sabin C. Review of life expectancy in people with HIV in settings with optimal ART access: what we know and what we don't. J Int AIDS Soc 2012;15:18076

40 Nakagawa F, Lodwick RK, Smith CJ, et al. Projected life expectancy of people with HIV according to timing of diagnosis. AIDS 2012;26:335-43

41 Hunter E, Perry M, Leen C, et al. HIV testing: getting the message across - a survey of knowledge, attitudes and practice among nonHIV specialist physicians. Postgrad Med J 2012;88:59-65.

42 Pillay TD, Mullineux J, Smith CJ, et al. Unlocking the potential: longitudinal audit finds multifaceted education for general practice increases HIV testing and diagnosis. Sex Transm Infect 2013;89:191-6.

43 Davies C, Gompels M, May M. Use and effectiveness of HIV indicator conditions in guiding HIV testing: a review of the evidence. Int STD Res Rev 2017;6:1-27.

44 Montoy JCC, Dow WH, Kaplan BC. Patient choice in opt-in, active choice, and opt-out HIV screening: randomized clinical trial. BMJ 2016;532:h6895.

45 Federman DG, Kravetz JD, Vasquez LS, et al. Improving human immunodeficiency virus testing rates with an electronic clinical reminder. Am J Med 2012;125:240-2.

46 Schrantz SJ, Babcock CA, Theodosis C, et al. A targeted, conventional assay, emergency department HIV testing program integrated with existing clinical procedures. Ann Emerg Med 2011; 58:S85-8.

47 Goetz MB, Hoang T, Bowman C, et al. A system-wide intervention to improve HIV testing in the Veterans health administration. J Gen Intern Med 2008;23:1200-7.

48 Menza TW, Hughes JP, Celum CL, et al. Prediction of HIV acquisition among men who have sex with men. Sex Transm Dis 2009;36:547-55.

49 Sharghi N, Bosch RJ, Mayer K, et al. The development and utility of a clinical algorithm to predict early HIV-1 infection. J Acquir Immune Defic Syndr 2005;40:472-8.

50 Joore IK, Twisk DE, Vanrolleghem AM, et al. The need to scale up HIV indicator condition-guided testing for early case-finding: a casecontrol study in primary care. BMC Fam Pract 2016;17:161. 